\title{
Case 2: The European Citizen Campus
}

In this chapter, we focus on the implementation of the EU's cultural programmes and explore what kinds of conceptions of Europe are constructed in the framework of an individual EU project. The European Citizen Campus (ECC) received funding from the Culture programme between 2013 and 2015. EU projects are used as channels to engage participants in the Union's activities, and as such, they can be seen as core elements of the EU's politics of belonging. In the chapter, we examine the performative and discursive construction of Europe and the 'European' as well as the notions of European citizenship as a part of this construction at different levels of the project.

The ECC was a student exchange project whose main coordinator was a Berlin-based organization that provides services for students in higher education. Other partners were similar organizations at local, regional, or national levels in Belgium, France, Germany, Italy, Luxembourg, the Netherlands, and Portugal, including two universities, eight organizations responsible for student services, two national umbrella organizations, and six regional or local organizations. In the summer of 2014, the project organized six art laboratories in universities or other institutions of higher education located in the partner countries. Based on their applications, 114 students from the seven countries were selected to participate in the laboratories. The core concept of the project was European citizenship, and the themes of the laboratories were viewed as "thematic variations of European citizenship" (Detailed description n.d., 4). The themes were addressed through various art genres in the laboratories, which were led by 12 artists. These themes were identity (art genres used in the laboratory: visual arts), roots (illustration, sculpture made from waste material), home (painting, crossover), conflict (visual arts, clay works, crossover), freedom (photography, optic media), and dialogue (music, dance).

We begin by introducing the research material and methods. After this, we explore the notions of Europe produced in the meso-level discourses related to the ECC. These discourses are produced by the organizations involved in coordinating the project before, during, and after it, and they concretize in the materials created for the project and in the implementation practices. Next, we analyze the micro-level EcC discourses - the project participants' notions of Europe and the 'European'. This analysis is divided into three parts. First, we 
explore the participants' perceptions of Europe defined by history, unity, diversity, geography, and borders. After that, we examine how the participants construct their own relation to Europe by referring to transnational mobility and interaction. Finally, we investigate how the participants understand citizenship in the context of Europe and the EU. The chapter concludes with remarks placing the meso- and micro-level discourses in the macro-level context, consisting of the EU documents on the Culture programme (see Chapter 3 ).

\section{2 Collecting Data and Conducting Field Research in the Ecc Project}

Our analysis of the politics of belonging in the Ecc context is based on an ethnographic study that includes interviews, observation, and research material consisting of texts and images created within the ECC project. The materials produced at the meso and micro levels of the project enable indicating the differences and similarities in the notions of Europe and exploring identifications with it constructed at these levels. The meso-level data includes texts produced by the organizers of the ECC project, regarding planning, presenting, and reporting on it. The most important of these is the Detailed Description (n.d.), which was attached to the project application; it is a text written by the organizers explaining their core ideas and forthcoming activities. This data also contains a catalogue of the art exhibition included in the project (Art Catalogue 2015) as well as a declaration (Antwerp Declaration 2015) made and published at the dissemination conference held at the end of the project. The micro-level data was mainly collected from participants in one of the aforementioned laboratories, the Roots lab in Strasbourg in July 2014. The fieldwork entailed observing two workshops and other activities at the laboratory over four days, writing a field diary, taking photos, and conducting nine interviews with 11 participants. In addition, the researcher had the opportunity to conduct informal discussions with the participants on various topics in the course of the laboratory.

The Roots lab programme consisted of workshops that ran daily from 10 am until $6 \mathrm{pm}$. On one day, there was a visit to the museum of the illustrator Tomi Ungerer with a film screening and presentation about him in the Strasbourg museum of modern and contemporary art. The participants were mostly in their early twenties and many of them studied art in some form but also other subjects. They came from Western Europe, because the project partner countries were located in this part of the continent. In general, more women than men participated: in the Roots lab, 20 of the participants were female and four male; in the other laboratories, slightly more than two thirds (17-18) of the 
participants were female, except in the Home lab, with a 1:1 ratio of male and female participants.

In the Roots lab, the participants were divided into two workshops; in both, participants eagerly volunteered to be interviewed once they had heard about the research. Three interviewees participated in the workshop making sculpture from waste material, held in the main building of the University of Strasbourg and led by a crossover artist. The other eight interviewees participated in the illustration workshop, led by an illustrator at the Strasbourg École supérieure des arts décoratifs, which is part of the Haute école des arts du Rhin. The interviews (ten female interviewees, one male) were conducted either during workshop breaks or in the evenings on public premises. They were held in English and lasted approximately 30 minutes. The interviews started with questions about the participants' initial expectations of the laboratory and what they had been doing in the project so far. After this, the questions focused on 'roots' as the topic of the laboratory and 'citizenship' as the topic of the project. The last question invited the interviewees to anticipate the effects of the project in their lives and whether they thought that participating would empower to act on issues important for them.

In addition, we were allowed to use research interviews that were conducted for a master's thesis by Janine Fleck (2015) with the participants of the Home lab in Freiburg in July 2014. Four participants, one woman and three men, gave their consent to use the interviews. The questions in these interviews explicitly addressed the idea of European identity in relation to home - the topic of the laboratory - intercultural exchange, and art. Interviews were conducted in French, English, and German.

Our ECC material additionally included thematic writings by eight project participants, four women and four men. Writing invitations were sent to all those participants who had agreed to give their e-mail addresses to the researcher. The participants were invited to write about their experiences in the project without giving any further instructions. One of the thematic writings related to participation in the Conflict lab, two to the Home lab, and the remainder to the Freedom lab.

The ECC data also includes motivation letters written by German applicants when they were applying to join the project. Eleven applicants (eight women, one man, and two anonymous) gave permission for us to use their motivation letters for research purposes, and their letters were forwarded via e-mail to the researcher by the project organizers. We do not know whether all of these applicants were accepted, but in this chapter, all the applicants are called participants because preparing and sending an application can be seen as a way of participating in the procedures of the project. 
Additional ethnographic material was collected through participant observation in the dissemination conference of the ECC project in Antwerp in June 2015, at which one of the authors was invited to present research findings. The same researcher also observed the art exhibition organized as part of the conference and presenting a selection of the art works made in the laboratories. This material includes photos of the art exhibition and notes about the conference presentations.

In the following analysis, the interviews from the Roots lab are numbered 1-11 and the ones from the Home lab are numbered I-IV. The thematic writings are coded TW1-TW8 and the motivation letters are coded ML1-ML11. The interviews were transcribed and the quotes from the interviews and texts in French, German, and Italian translated by the authors. We take a conceptual approach (Wiesner et al. 2018) to the data, focusing on the meanings given to Europe (see Chapters 1 and 2). Our data-driven analysis is based on close reading that enabled clustering the variety of thematic categories interpreted in the research material.

"A Sense of European Identity": Constructions of Europe in the Meso-level Ecc Discourse

A poster advertising the project illustrates the key idea of the ECC: European citizenship. The text of the poster invites the reader to "give your definition about European citizenship" (see Figure 5.1).

The purpose of the ECC project was "to raise general awareness and concern on the issue of European citizenship and to develop new visions to this concept from a student perspective (Detailed Description n.d., 8). Art had been chosen as the heart of the project, as a way to "create a new focus on the reality of citizenship" (ibid., 1). The project description envisaged that participants' debates on citizenship were to be stimulated through the simultaneous presence of two art genres in each of the laboratories (ibid.). According to the Antwerp Declaration $(2015,4)$ published by the project organizers at the dissemination conference, the "[artistic] engagement enriched the ongoing political discourse and created an emotionally-personal level, without it the EU citizenship would have remained an abstract construct". In the implementation of the project, citizenship was approached in different ways. For example, in the Roots lab, citizenship was not present in discussions or practices, whereas, according to the Art Catalogue $(2015,57)$, the artists directing the Conflict lab "accompanied and encouraged micro-conflicts among the participating students, in order to bring out the contradictions of living as citizens of Europe". 


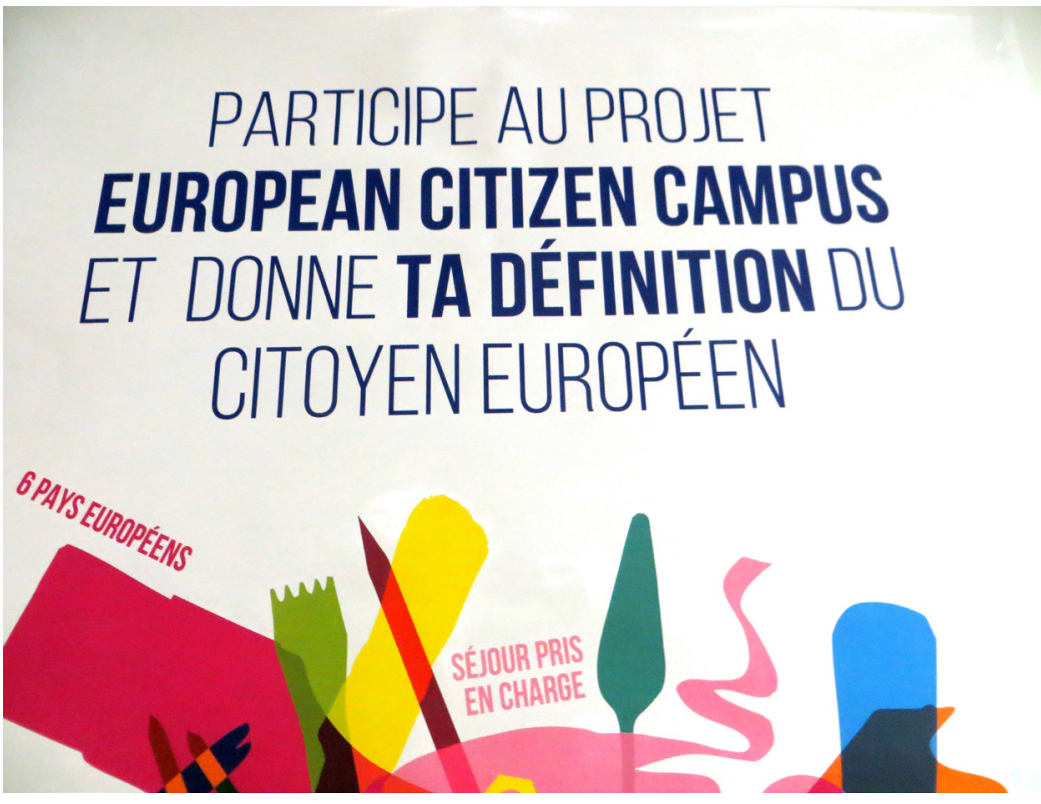

FIGURE 5.1 A poster (detail) that advertised the ECC in Strasbourg in 2014 on the wall of the student canteen where meals for the Roots lab were served.

PHOTO: KATJA MÄKINEN

In the Conflict lab, citizenship was viewed as a contested condition that is not the same for everyone, even though citizenship is often understood as a status that presumably guarantees citizens' equality.

The locations of the laboratories were envisioned to support "reflection on new European Citizenship visions" (Detailed Description n.d., 2). Cultural heritage sites were deliberately selected, because "European citizenship and European cultural heritage are considered to be complementary concepts as both issues are related to questions about roots, past, provenance, identity etc." (ibid., 6). The selected locations were university sites, since "[a] university site is the best suited starting point for the promotion of active European citizenship" (ibid., 3) and is "naturally predestined for an artistic reflection on the European citizenship model" (ibid., 5). This is because universities are seen as meeting places of "citizens of the world" (ibid., 3), supposedly enabling manifold debate and providing opportunities for intercultural dialogue, sharing knowledge and values, developing deeper understanding of diversity, and fostering equality.

In the ECC, developing the participants' European identity was an explicit aim. The purpose of the laboratories was to stimulate "an awareness building process on Europe's cultural richness based on its diversity and the development of a sense of European identity [...] amongst the project participants" 
(ibid., 8). In the final conference of the project, the plan was to discuss, based on the experiences gained in the laboratories, "the essential components of this European identity" (ibid., 7). Moreover, identity was defined as one of the six dimensions of citizenship, and thus one laboratory was dedicated to it. In this laboratory, identity was understood as involving constant change, quest, dialogue, difference, and confrontation, and as becoming recognized "in the public space through forms of cultural mediation and (artistic) expression" (Art Catalogue 2015, 7).

European identity was understood in the meso-level ECC texts as a cultural identity reflecting the cultural richness and diversity of Europe. Because some of the project organizers were specialized in providing cultural services to students, it is understandable that the cultural dimension of identity was emphasized. Nevertheless, a project on European citizenship could focus on a myriad other questions: access to citizenship; fundamental, social, political, and cultural rights; or various forms of civic participation in different fields. Admittedly, identity is commonly understood as one dimension of citizenship. For democracy to function, we need a demos, a democratic collective subject that recognizes itself as such and is able to use power in democracy. This means that a sufficient part of the population identifies with their political community and each other. When defining citizenship, questions of both identity and difference need to be considered so that diverse voices can be heard in decision-making. In the ECC discourse at the meso level, the relations between citizenship and identity are not, however, elaborated on further.

In the meso-level materials produced by the ECC coordinators, Europe was seen as an entity in the making (see also Chapter 6). The central role of citizens in this making was emphasized, which is not surprising given that the topic of the project was European citizenship. The Detailed Description (n. d., 1) explicitly defined Europe as "an ongoing process of construction [that] should be shaped and defined by its citizens". According to the project description, "[y] oung people, in particular, have a special interest and concern about what kind of Europe they live in" (ibid.). Therefore, the project sought to explore questions around students' European identity and their engagement in the social and political life of the EU. It especially underlined the role of universities and student service organizations as the first objective of the project was to highlight "the vital role that universities and their partnering student service organization can play in the development of a European identity amongst young people" (ibid., 3). Above all, the project description emphasizes students' perspective on European citizenship. Because students are personally affected by the European integration process, both in their studies and as citizens, their contribution to "promotion of active European citizenship and the creation of 
an ever closer Europe" (ibid., 1) is seen as important. The wording "ever closer Union among the peoples of Europe" originates from the Treaty of Rome (1957) and is frequently used in the EU documents. This key phrase implies that Europe is understood as a continuous process of integration and community construction.

Europe and its construction were understood as objects of public debate in the meso-level ECC discourses. The ECC project was seen as a channel for the participants to contribute to the public debate on Union citizenship, as explained in the Detailed Description (n.d., 3): "ECC starts a creative process on different vision(s) of the European citizenship concept seen by student eyes with the purpose to stimulate debate on this issue with the wider audience". According to the Antwerp Declaration (2015, 6), "[s]tudents and their artistic potential should be recognized as a resource for political dialogue in Europe". Moreover, the declaration claims that "[s]tudents are very keen [...] to contribute to the general political discourse via their art work" (ibid., 3). This was also clearly stated in the Art Catalogue $(2015,2)$ :

With the ECC project we bring in the voice of European students in the political debate on the identity of the European Union. [...] the creative process of art production in which students from all academic disciplines took part will enrich the often abstract political discussion on European citizenship.

According to these quotes, the ECC sought to help make students' voices heard in debates on the identity of the EU and on European citizenship, which exemplifies the entwined relation between identity and citizenship. Moreover, in these texts, Europe is frequently equated with the EU.

The public dimension was manifested in the art exhibition, which presented some of the art works produced in the laboratories. The exhibition was circulated in the partner countries and at the final dissemination conference in Antwerp in June 2015. The aim of the exhibition was "to give an overall view and new visions on European citizenship as well as to stimulate a debate on this topic with the broader public" (Detailed Description n.d., 2) and to "enhance the European visibility of the project and to reach out to a wide public" (Detailed Description n.d., 6). Indeed, public debate is essential if citizenship is understood as political agency. Politics is done in the public sphere through acting together and sharing acts and speech (Arendt 1998, 180-183, 198). In the research data on the ECC implementation, however, the notion of citizens' public activity remained invisible, as our analysis will show.

The analysis of the meso-level ECC discourses shows that the project organizers practiced three types of politics of belonging. First, they explicitly aimed 
to develop participants' European identity and, second, to involve participants in one of the key institutions of the Union: citizenship. Third, the project as such can be understood as a platform for engagement at the European level. The ECC can therefore be interpreted as a technology of agency (Walters and Haahr 2005, 124) embedded in the EU's participatory governance. The students were invited to become active collaborators in the process of 'European construction' and simultaneously to feel partnership with and belonging to Europe and the EU.

“That Would Really Be Europe": Europe Perceived by Project Participants

The notion of Europe was central in the participants' interviews and motivation letters, and to a lesser extent in the thematic writings. This can be explained by the obvious fact that the participants were involved in a project funded by the EU. Particularly in the motivation letters, the centrality of Europe was not surprising: one would suppose that in an application for an EU project about European citizenship, it is a good idea to discuss Europe. The thematic writings focused mostly on the participants' experiences of encounters with other participants, visiting a new place, and making art. In three thematic writings (тW 1, 4, 7), Europe was discussed more extensively.

In the interviews in the Roots lab, Europe was one of the main themes the interviewees raised, besides art, themselves as participants, and other participants. The role of Europe was central to their experiences of this laboratory, even though the interviews did not include any questions about Europe, nor was it explicitly present in the practices of the two workshops. The interviewees mentioned Europe mostly when answering questions about roots and citizenship, that is, when pondering the core topics of the ECC project and the laboratory. This is partly explained by the fact that the researcher conducting the interviews mentioned European citizenship in this context. The participants did not proactively mention citizenship and found the question about it confusing. When the interviewees asked for clarification, the interviewer explained that because the topic of the project is European citizenship, this study explores their conceptions of citizenship. The questions in the interviews with the participants in the Home lab deliberately focused on Europe and European identity. Hence, Europe was frequently discussed in these interviews.

Participants discussed Europe in close connection to the EU and sometimes the two terms were used as synonyms, which is common in political, media, and everyday discourses. For many participants, the EU appeared as 
something taken for granted, and one of the factors contributing to this, mentioned by several participants, is the Euro currency as an everyday practice. Some of them constructed their relation to Europe through the EU membership of their own home country: Europe feels like home because their homeland is an EU member state.

When defining Europe, some participants drew from history. In their view, Europe was also characterized by both diversity and unity. Geography and borders were other central elements in interviewees' notions of Europe. The roles of these three interrelated themes in the participants' constructions of Europe are analyzed in the following.

\subsection{History}

The venue of the sculpture workshop in the Roots lab was the main building of the University of Strasbourg, where the initial steps of the European integration were taken, as the Assembly of the Council of Europe had its first meeting there in 1949. According to the founding narrative repeated in the EU discourse, European integration was started in order to prevent new wars between countries in Europe, most notably France and Germany (see Mäkinen 2019). It is thus fitting that the assembly met in the Franco-German border area: the city of Strasbourg itself had faced several wars but also represented the potential for peaceful relations across national, cultural, and linguistic borders.

The role of Alsace in World War II and the initial phase of post-war integration was not discussed in the laboratory, apart from a very brief remark by the leader of the sculpture workshop, placing the topic of the laboratory "in the European context". He referred to "our roots [that] are broken because of the war" (Artist 1) and conceptualized the workshop as a revisit to that past. He connected roots as a topic to the history of Europe, that is, to World War II and the post-war cooperation. "We", the laboratory participants in the present moment, were linked to those past processes.

Two participants (7 and 9) in the sculpture workshop indicated that the teacher's remark helped them to link their art-making to the roots topic and the European context. Both participants referred to reconstruction and repairing the connections that the war had broken. Some of the art works made in the sculpture workshop indeed reflected the idea of Europe and its roots (Art Catalogue 2015, 52-55), whereas in the ethnographic data, there were no signs of connecting the roots topic with Europe in the illustration workshop.

A visit to the Tomi Ungerer museum and a film about him, included in the programme of the Roots lab, illuminated these aspects. In the personal history of the illustrator Tomi Ungerer, several layers of identity overlap: he was Strasbourgeois, Alsacien, and French. Alsace as both a battlefield and a multilingual 


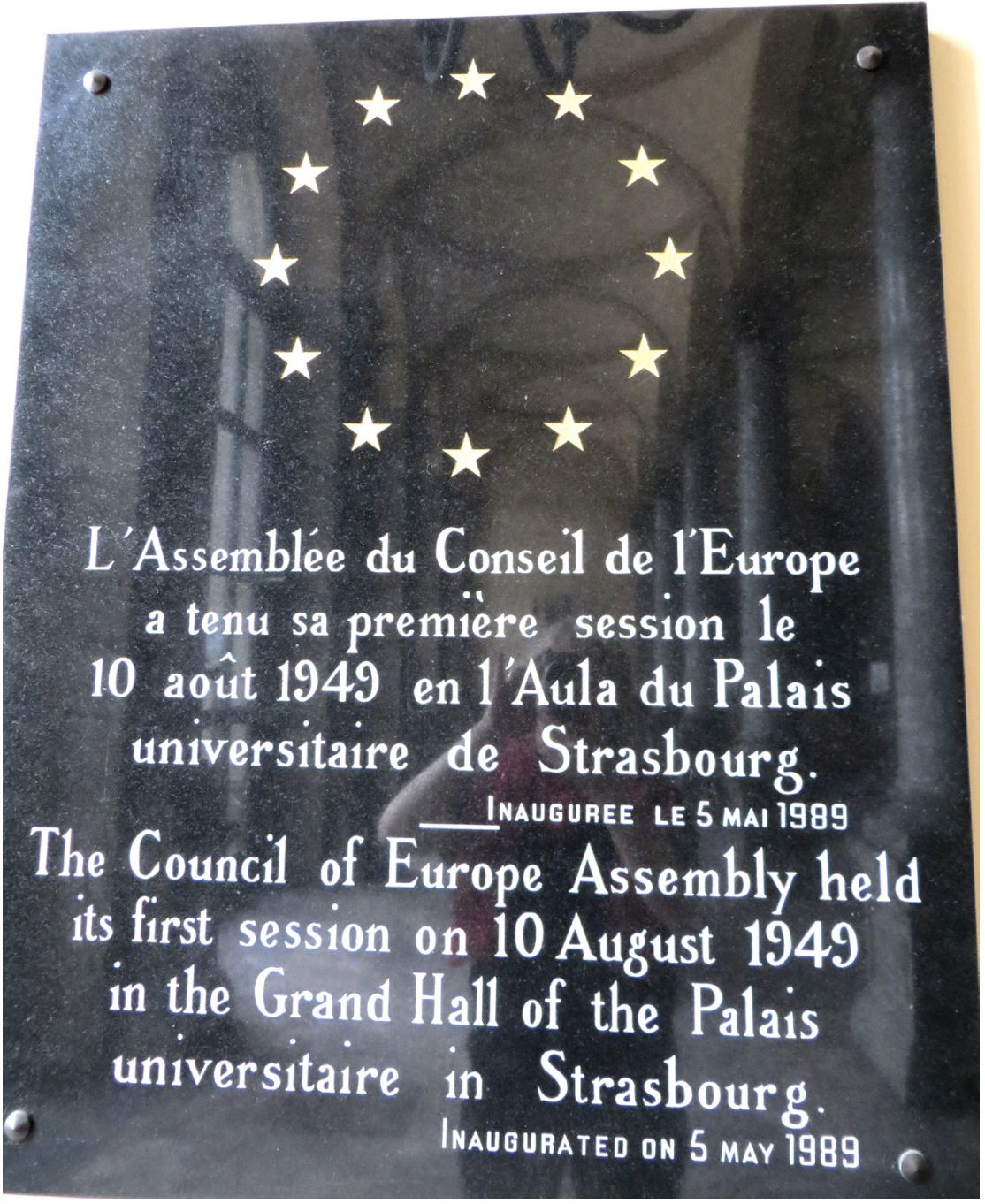

FIGURE 5.2 The plaque in the hall of the main building of the University of Strasbourg commemorates the first session of the Assembly of the Council of Europe. PHOTO: KATJA MÄKINEN

and multicultural border region between France and Germany played a significant role in the life and art of Ungerer, and he strove to improve Franco-German relations. Hence, the museum and the film offered opportunities to reflect on both roots and citizenship and their context embedded in Europe and its history. There was no time scheduled for discussing the museum and the film in the laboratory programme. Despite this, one of the participants connected the topic of roots and Tomi Ungerer in a comment published in the catalogue 


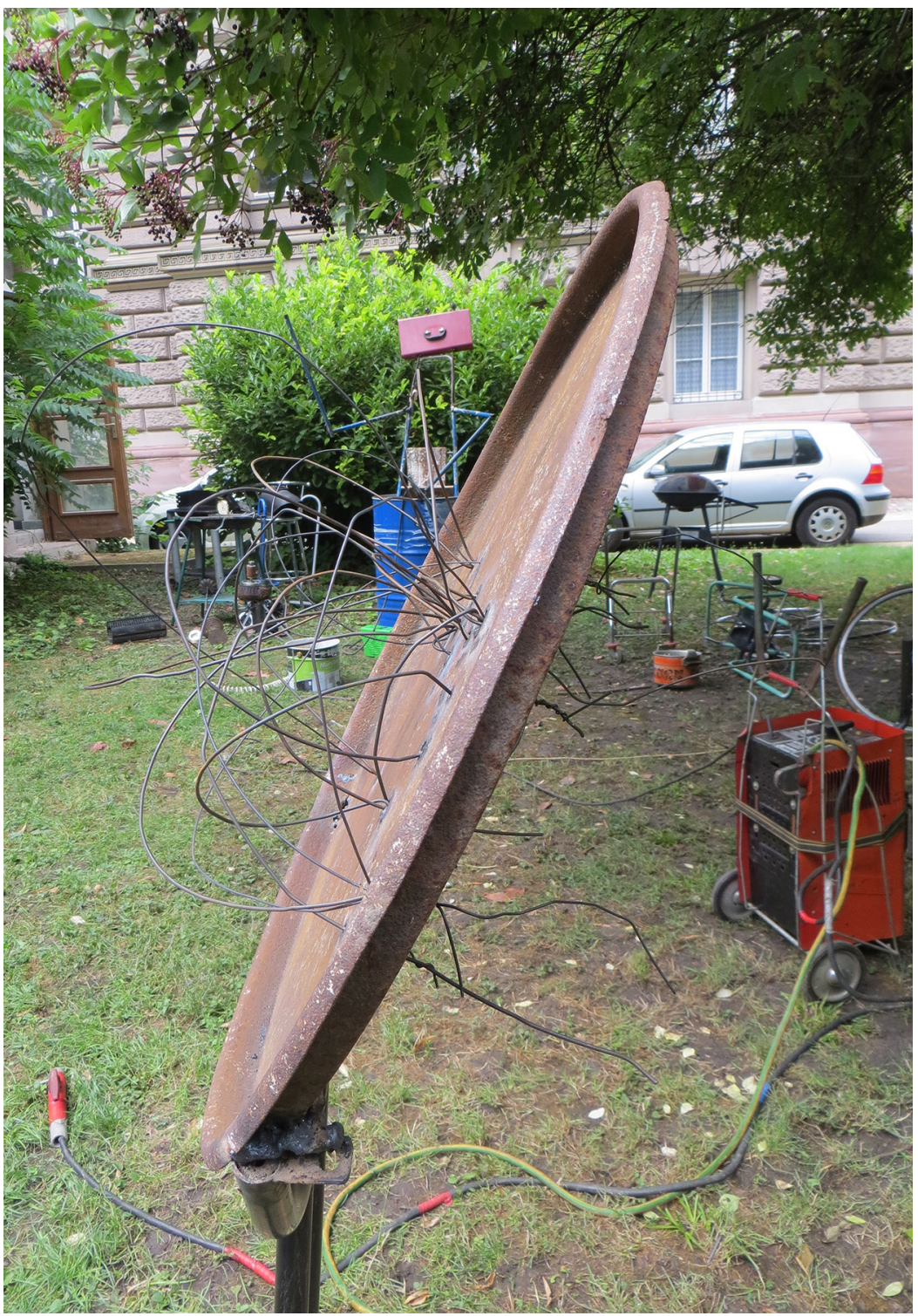

FIGURE 5.3 Roots of Europeans crisscross in an art work being made in the sculpture workshop. PHOTO: KATJA MÄKINEN

presenting the project and the art exhibition based on it (Art Catalogue 2015, 53):

My strongest experience in the ECC lab was watching the Tomi Ungerer movie. He had to change his life and language several times due to war... 
he has difficult roots and you can see this in his art. The movie made me understand why Strasbourg, where Tomi Ungerer was born, chose the topic 'roots'.

She also linked the roots topic and the personal history of Tomi Ungerer to Strasbourg as a place. In general, the interviews, thematic writings, and motivation letters dealt with history relatively little. One participant (ML7) pondered the idea of roots when living in Europe during the Euro crisis and related it to questions asking what is special about these roots and how they become a means of distinguishing from others. This participant wondered if roots could grow together in an intercultural sense to approach peace and solidarity, and how the next generation would perceive them. The reference to the next generation implies that the current moment is history for the next generation and that roots are not only about the past but also about the future and about relationships between people. The metaphor of growing refers to the conception of Europe in transformation. Furthermore, various participants (ML1; Interview II) referred to the integration of European states after the two world wars and the collapse of the Iron Curtain and the Warsaw Pact, which indicates the importance of borders and their changes in the history of Europe. The participants connected their conceptions of Europe to the transformation processes in its history and the relations between states in it, acknowledging that there are factors that can both unite and separate different people and regions in Europe.

\subsection{Unity and Diversity}

Within the ECC project, the diversity of languages was an everyday experience for the participants, as one of them described (Interview IV):

one sees, however, a unity, even though they speak a different language [...] Although there are different languages, they are almost the same persons. The persons, they are not different. One cannot say: she is French, she is Italian, and he is Belgian.

A spontaneous collective practice manifested this cross-linguistic 'we feeling' in the Home lab: "at the end of the day, the idea came [that] we say: 'we are Europe', in all our different languages [...] We had our flags of our countries painted on our hands" (Interview VI). Another participant confirmed that in the Home lab, besides small mentality differences, there were no differences between participants, which to him illustrated that particularly the younger Europeans are already "rather well adjusted to each other" (Interview II). 
According to the same participant, media, the internet, music, films, and art provide a "relatively broad common cultural basis" (ibid.) for European people in the younger generations. Indeed, as stated by a participant in the Roots lab, "we all come from different countries but I feel that we have much in common when we meet" (Interview 8).

For one of the participants, to be a European citizen meant a "strive for interculturality" and the ability to speak several languages. According to her, "every culture has a different feeling [...] people are different", and she finds "this kind of diversity" positive and interesting (Interview 10). Another participant - who wrote in this context that he speaks five languages - described himself as "a young European, who together with other young Europeans would like to discuss and form the future of our continent, aware of our diverse nations and our several commonalities" (ML1). He acknowledged both diversity and unity in Europe and, moreover, understood himself as an active agent in shaping Europe.

These experiences in the ECC project and other contexts illustrate that the participants often depicted Europe as an entity consisting of different countries and languages, yet sharing a lot in common - as "a big country made up of small countries" (Interview VI). The plurality of languages spoken in Europe was not viewed as something that separates people but as a source of diversity that can create a sense of unity: "I see it like a big country where we speak other languages, but we are all together" (Interview 2).

The unity of Europe was considered more visible when perceived "from another continent" (Interview 11), as the same interviewee went on to show.

I think if you are from another continent, you think Europe is quite close. The countries may be quite similar but I think even if France and Germany are quite close, there are huge differences. You can feel them but that doesn't mean that you can't cooperate, that doesn't mean that you can't get along with each other. [...] Sometimes the differences are good, and you have to keep them up because they belong to culture and identity.

Nevertheless, this participant pointed out that there are 'feelable' differences within Europe. In her view, these differences do not prevent cooperation, but are an integral part of culture and identity. Other participants agreed that when taking a closer look, the cultures in Europe are not similar - on the contrary, "many different peoples with their own languages and cultures are squeezed on our continent making it so diverse" (ML5). In addition, diverse ethnicities and religions were seen as part of Europe (ML9). Referring to countries beyond 
Western Europe, one participant underlined "how people from different places are something very different" (Interview V).

Identities are often constructed in relation to 'others' and by drawing distinctions. Thus, European identity is commonly approached by contrasting Europe to the rest of the world. In comparison with cultures outside Europe, such as in the United States, Asia, or Africa, the others appear "different" (Interviews 1, 2, IV) to some participants (see also Chapter 6). One of them thought that for a long time Europe has been more developed than the rest of the world, although other places are increasingly catching up. She said: "In other sections of the world, they have to learn so much. They live so different, they think different" (Interview 1). In contrast, this interviewee connected "our vision of the world" to principles such as equality, rights, and freedoms, which she said still makes Europe a popular immigration destination. The tremendously problematic perception of Europe as a higher form of civilization has been very influential but in the ECC data there were no other examples of this. Even this participant relativized her notions by recalling that there are problems in every part of the world and mentioning some of them in her own home country.

In contrast, some participants highlighted the cultural similarity between Europe, the Americas, and Japan. One of them perceived European identity as an outdated concept and preferred to speak of a 'Western identity' instead. He included the USA and Japan in this "Western cultural circle" (Interview II) because so much culture is imported to Europe from these countries. However, he noted that there are cultures with which he cannot identify and emphasized he was above all European and felt at home in European countries.

\subsection{Geographical Borders}

In addition, and related to history, unity, and diversity, the participants elaborated their conceptions of Europe in terms of geography and borders. Although participants often discussed Europe as the EU, their notions of Europe went beyond it: "Europe, after all, is bigger than the Union" (Interview V). Participants would have liked to include peers from Eastern, Southern, and Northern Europe in the ECC project "because that would really be Europe" (Interview V; also Interview 7; TW4). They hoped to meet participants from all over Europe, not only the EU member states, implying that their understanding of Europe was larger than the EU. Moreover, some of them thought that the project should have participants from other parts of the world, such as North and South America, Asia, and Africa (Interview II; IV).

One of the participants paid attention to the changes in the geographical perception of Europe between generations. This participant from Western 
Europe assumed that for her grandparents "Europe does not go as far east as it does for me" (Interview 5). She was glad that in the current imaginaries, the eastern border of Europe was moving further east. She constructed an inclusive notion of Europe, saying that "we should not be afraid to let other people in" (ibid.).

The changing borders within and around Europe, discussed by the participants, can be seen as part of their conceptions of Europe. A piece of video art made in the Home lab represented how the borders in Europe have changed during centuries. For example, Germany was constituted from small states in the nineteenth century, and in the 1990s, Czechoslovakia was peacefully divided whereas Yugoslavia broke up through war, as a participant involved in the making of this artwork explained (Interview II). Moreover, the morphing technique used in this video-art piece shows people's faces merging into each other. It represents a process of continuous, never-ending change, performing that "the Europeans are very similar", according to this participant (Interview II).

Internal borders within the current states in Europe construct the participants' perceptions of the continent. For example, one participant pointed out that there are regional differences even within one country and one language (ML5). One interviewee observed a dynamic in which Europe first grows together due to the EU integration and then states (re-)emerge within Europe, such as Scotland, Catalonia, the Basque country, or Fleming and Walloon regions in Belgium (Interview II). Moreover, if Turkey eventually joins the EU, "the Kurd question becomes a European question" (Interview II). Such questions of regional sovereignty shape the image of Europe and its internal borders.

Several participants supported the idea of a 'borderless Europe'. For them, the ability to cross state borders without formalities makes everyday life easier for people like tourists, residents of the border areas, and exchange students (e.g. ML9). One interviewee had a vision of Europe in which the borders were erased altogether (Interview V). This idea again exemplifies a conception of Europe's shifting borders: they shifted in the past and they can shift in the future. While participants greatly appreciated the right to free movement across state borders, some of them regarded it as boundary-making, dividing EU citizens and non-EU citizens (Interview $5 ; 7$ ). This issue was also raised by a participant speaking at the final conference, reminding listeners that free movement is not everybody's right. One participant specifically criticized the EU's "governmental institutions", such as FRONTEX, for granting “'our' freedom on the 'inside" by drawing "a strong distinction against the 'outside' (meaning 


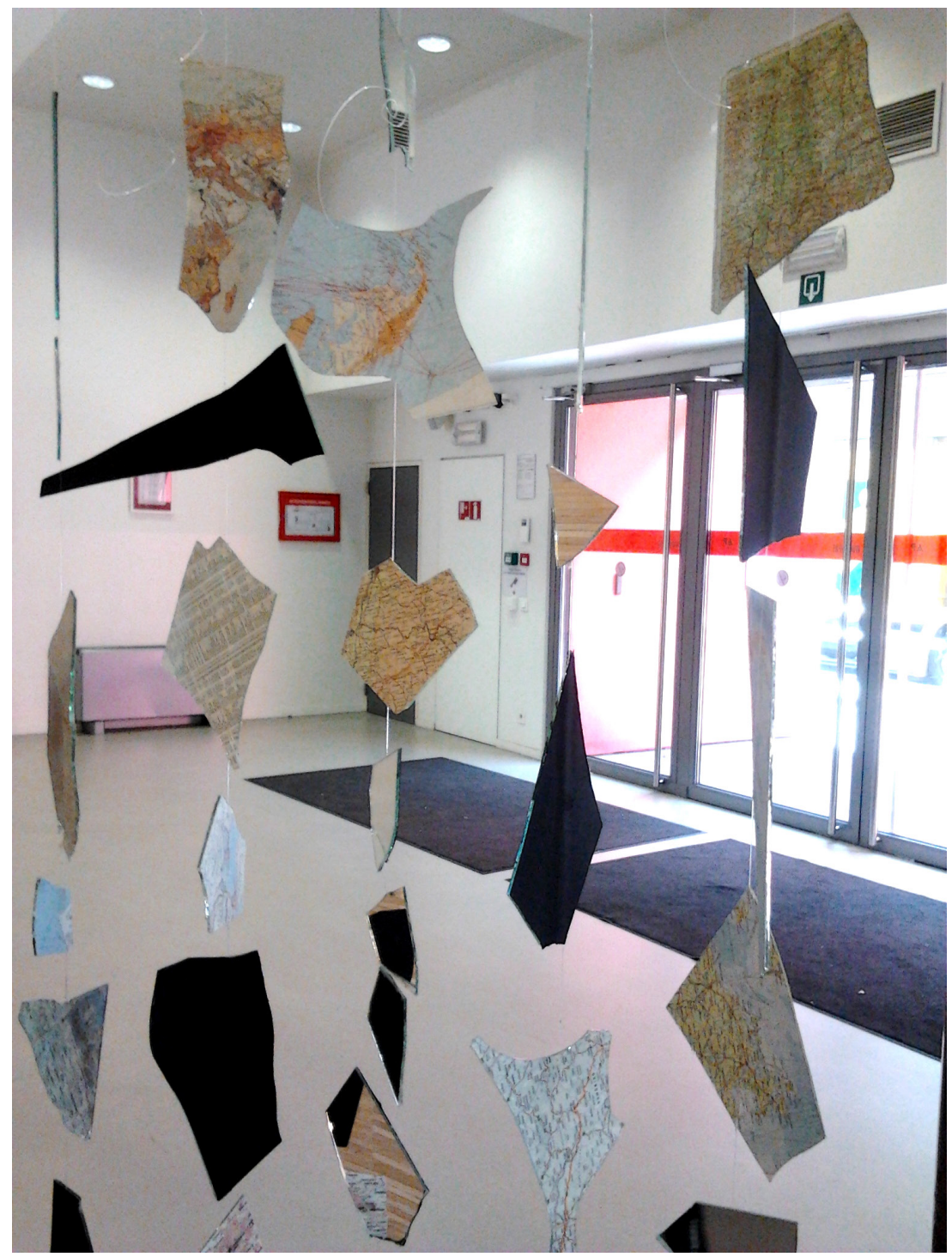

FIGURE 5.4 Shifting geographies of Europe in the ECC art exhibition at the dissemination conference in Antwerp.

PHOTO: KATJA MÄKINEN

non-EU migrants and so on)" (Tw4). In general, the participants were in favor of an inclusive Europe but some of them recognized that Europe is exclusive for many. 
The participants' own relationship with Europe was commonly conceptualized through travelling, student exchange, youth exchange, international internships, and other international experiences. Participants firmly supported cross-border mobility without formalities, and mentioned the Euro currency as a factor that facilitates travelling. Interviewees saw it as important that projects, such as the EcC, enable travel for students who usually do not have enough money to do so (e.g. Interview $5 ; 6$; 7 ; 10; II).

Mobility was also significant for the participants' European identity and belonging, as one of them explained (Interview 9): "I really feel connected because of that [...] I really feel a citizen of Europe because of that". For instance, living and studying abroad and using foreign languages were perceived as fostering the feeling of Europeanness, as exemplified below (Interview 6):

I don't know when it started but it started quite a time ago, and I started my studies [...] and because we are all so multicultural, and then I started to feel more European than German, and I really have the feeling now to be more European than German. And this language switching thing is not a problem anymore if we talk French or German or English to each other, and I even get some Italian words. It's quite a nice experience.

Similarly, another participant emphasized that her identity includes several aspects that are not mutually exclusive: "it's a personal identity thing [...] It was not either-or, it's not so black and white. I think it was very nice. And I love the whole language switching and being able to travel" (Interview 7). As these examples show, several participants discussed their European identity in relation to their national identity. It was typical to discuss both together, as this participant did: "I feel that I am French but I feel that I'm European too" (Interview 9). Some participants identified themselves rather as Europeans than their respective nationalities (Interview 6; 7; II). In sum, as one of the participants expressed, for young people, it is increasingly "normal to feel European" (Interview 5).

According to the participants, mobility enables meeting people from different countries and learning about new cultures. Some participants already had experiences of mobility and transnational encounters through other EU projects, student exchange, or voluntary work, whereas for others the ECC project was a new experience of acting on this scale. Networking and interacting with new people and speaking foreign languages was one of the reasons that many participants wanted to join the project: "I joined this programme because I wanted to meet people, European people" (Interview 9). 
The participants' notions of Europe were closely linked with their perception of other participants, whose different backgrounds were viewed as representing Europe (the audiences of the ECOC events had a similar approach to Europe, see Chapter 4). They saw Europe as consisting of encounters with other Europeans from different places (similarly to the younger EHL visitors, see Chapter 6). EU projects like the ECC were perceived as platforms for interaction and communication with people from different countries. According to the participants, "it's always interesting to confront our point of view with another, to just be with other people, to talk, to interact" (Interview 9). The language skills facilitating communication in the project were mentioned by several participants, as was an open-minded and interested attitude - the willingness to "have contact with the others" (Interview 1) despite language difficulties.

The participants felt that encounters with other participants brought them knowledge: "The fact that I have learned things just because we are talking, it's really good" (Interview 3 ). They repeatedly highlighted the role of other participants in learning: "I have experienced from others much about culture, cities, ways of life, eating, political systems of their regions or countries" (TW3). Such personal encounters could cause a positive clash, as one participant noted (Interview 11):

Always when you meet people from other countries [...] you always learn something about yourself, about others, about cultural thinking, feeling, standards, morals. It's like a clash sometimes, but in a positive way.

The notion of clash implies that the encounters and the learning experiences they spark can expose participants to something new and different. Meeting new people and experiencing new places and situations also encouraged participants to appreciate cultural diversity, as explained by one of the interviewees: "we definitely do learn about each other and about being different. Cause we are all different" (Interview 1). Encountering this novelty, diversity, and difference effects participants' self-reflection, as highlighted by one interviewee (Interview 4):

to find in myself a new source, to do new things, and to come back in my home bigger and enriched. [...] to see people from other countries permits me to re-evaluate myself and to know what I want and to confront to new cultures and new ways of thinking. To see with other eyes.

Personal interaction in the project could foster a sense of belonging. One participant explained how during the project, she had "been able to learn how to 
love other people, different people, different cultures" (Interview 3). Due to the encounters in the project, another participant felt "more able to connect with other places" (Interview 4). The participants conceptualized their encounters as contributions to developing openness, tolerance, understanding between people, co-existence, citizenship, and peace: "[w]e should not be prejudiced and not be afraid" (Interview 5).

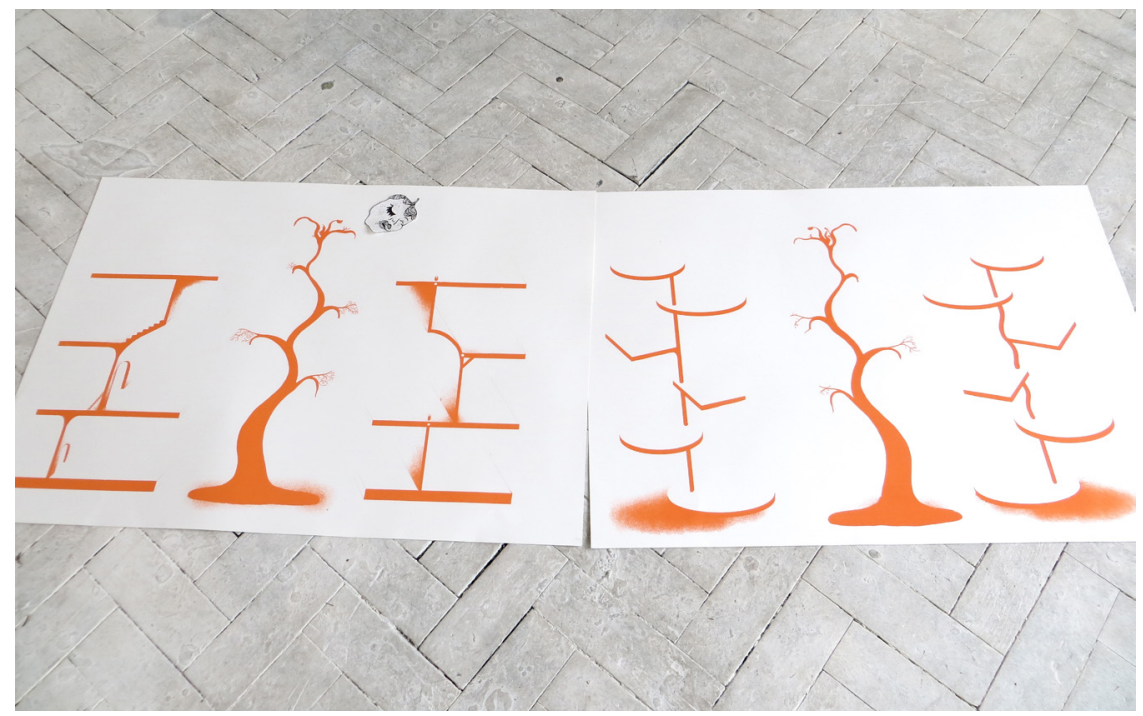

FIGURE 5.5 The empty trees in the illustration workshop are waiting for the participants' images and texts expressing their roots.

PHOTO: KATJA MÄKINEN

Some of the participants saw that the ECC affected their sense of belonging to Europe. The interaction in a group made up of members from different countries was conceived as a major factor here, as described by one participant: "Yes, of course it has developed. Because we created a European group and we acted and worked as it" (Interview VI). In a similar vein, another interviewee argued that projects like this are building entwined roots between different languages, cultures, and ways of thinking in Europe (Interview 9). However, other participants were more uncertain about this effect of the project: "I am not sure if I discovered there my identity as a European" (Interview V).

Nevertheless, the participants experienced that Europe becomes more concrete through the ECC and other similar projects. For one interviewee, the project proved that Europe is not just an abstract idea but can manifest itself in projects of considerable scope. "Thus, it has shown us that the partnerships are possible and feasible", she explained (Interview IV). The same participant argued that 
the "project can rehabilitate the vision that people have about Europe" and "give again belief in Europe" (ibid.). She contextualized the ECC in a situation after the election of the European Parliament, which had "showed that many people are against" (ibid.) Europe - that is, the EU. Similarly, another participant linked the project to EU integration pointing out that "besides the political and economic connections between states, it is the people who have to live and experience these connections in a small scale" (ML1). He thought that "the ECC seizes precisely this scenario" (ibid.) as it enables dialogue and cross-border networking on a human level. The participants explained that the European aspect of their own identities is attached precisely to this type of transnational practice.

However, as noted earlier, several participants regretted that all the project participants came from Western European countries, and one participant pointed out that the EU projects themselves, such as the ECC, can be interpreted as drawing a distinction between those who come from a "privileged country" (TW4) and those who do not. Admittedly, people from different member states do not have equal opportunities to participate in EU projects due to the burden of travel costs or other financial differences. Participation in EU projects - like any participation - requires resources that differ according to factors like economic or social background, class, education, and age. For example, the ECC was only aimed at students in higher education.

\section{Citizenship as an Element of European Belonging}

Launching the citizenship of the Union is a prime example of the EU's politics of belonging, and EU projects like the ECC can be seen as attempts to give practical contents to the concept of Union citizenship and thus also to the idea of Europe as citizens' community. Citizenship was a core term in the meso-level Ecc discourses and closely intertwined with the notion of European identity. Similarly, the macro-level EU discourses endow citizenship with a major role in the EU's politics of belonging, aiming to bring citizens closer to the EU and each other (see Chapter 3). Next, we discuss how the participants understood the notion of citizenship in the EUropean context and in their own relation to Europe and the EU.

Although the theme of the ECC project was European citizenship, participants scarcely discussed citizenship itself. Nevertheless, some of them perceived Europe as a meaningful frame of citizenship. Mostly they were participants in the Roots lab, since their interviews included an explicit question about citizenship. However, most of the interviewees found it difficult to think about citizenship in the European context. 
One participant explained that the idea of European citizenship is "difficult because Europe is so big and there're so many interests" (Interview 5). She felt that civic participation in general was more feasible in a smaller frame because it was easier to get to know the relevant information and actors related to the issues which one seeks to influence. Another participant agreed: "difficult to answer because [...] I have not a large vision of Europe. So, I don't know what it means to be citizen of Europe" (Interview 8). For her, citizenship was a way to live peacefully in a city and "to build projects about a better life, or maybe solidarity" (ibid., 8). Despite this local framing, she saw a correspondence between the local and the European scales when arguing that "maybe this kind of project we are living in this week is a way to do this more in a bigger vision" (Interview 8). She is the only interviewee who expressed that EU projects such as the ECC can have such a direct role in enhancing citizenship.

Participants very rarely recognized the political potential of citizenship. However, three interviewees (Interview 2; 5; 6) found it important that European citizens can elect members of the European Parliament. It needs to be noted, however, that the interviewer gave voting as an example of citizenship's political aspects when the interviewees asked her to clarify the question about citizenship. These participants argued that it is important to be involved in decision-making concerning the rules that we live by and voice one's opinions by voting.

Although the interviewees were asked whether they thought that participation in the ECC project will empower them to take public action, the effects of the project were mainly understood on an individual level, as demonstrated below (Interview 5):

On a political level, I don't think it's gonna influence me, I think it's more gonna influence me on a personal level, it's again another help to for me to get more creative again [...] expressing myself [...] But being active politically, so far, I don't think this is gonna help me much.

Another participant agreed that participation in the project supported neither citizens' political involvement in the EU nor identity building (TW4):

from my point of view the goal of construction a 'common European identity' or the idea of citizen participation is not achieved with programmes such as the ECC. Despite the fact that I am happy that EU granted me this treat, it does not make me feel as a citizen of a common European Union or as if I could with this get politically involved in it. I just got another confirmation that a lot of the privileges I enjoy are merely a product of 
hegemonic inheritance. [...] Furthermore, there was never any critical reflection upon what it means to be European.

Even though the official ECC discourse emphasized the debate on Europe, this participant experienced that critical reflection about Europeanness was lacking in his laboratory. The participant observation in the Roots lab supports this impression that unlike the meso-level plans, the programme did not generate discussion about the idea of Europe or citizenship.

Some of the participants discussed citizenship in a way that reflects an understanding of Europe as a privileged place. They conceptualized their "privileges [as] a product of hegemonic inheritance" (TW4), emphasized that in Europe certain matters related to rights and equality are more advanced than in other places (Interview 1), and perceived citizenship as a right that their ancestors have fought for, and felt lucky "compared to [...] other countries" (Interview 4) to have this right, which is not necessarily available to people outside Europe. They noted that "European citizenship" does not apply even to all countries within Europe (Interview 7), thus distinguishing between Europe and EUrope and recalling the plurality of Europe. These comments reflected the fact that nationals of European states that are not EU members and third-country nationals in the member states are not entitled to EU citizenship.

Although some participants mentioned the power dynamics intrinsic in citizenship, they were more likely to discuss the effects of participating in the project on their personal lives, such as learning new skills and getting new information for their studies, forthcoming professions, plans for similar projects, student exchange, and making art. They also repeatedly highlighted that the opportunity to interact with other participants and learn about their backgrounds would have lasting effects on them. This was framed as interpersonal dynamics at the individual level in the private sphere rather than as joining forces for citizens' activity seeking to make claims, use power in the public sphere, or take part in decision-making.

Instead of political action in the public sphere, some participants understood citizenship as a status. For example, one participant with a multinational and multilingual family background was wondering why she could not simply have only the European citizenship, instead of needing to decide for one of multiple national citizenships (ML8). She also linked European citizenship to collective identity construction and felt European because of her background. In her specific case, the status of EU citizenship contrasted with the exclusive frameworks in which national membership is commonly defined, and offered an alternative way of experiencing full membership- with and despite her multiple affiliations and allegiances (see also Čeginskas 2016). Another participant 
explained how "holding EU citizenship was offering me benefits" (ML3) when living abroad. As discussed above, mobility rights were frequently emphasized as a concrete benefit to EU citizens, which indicates that the understanding of the Union citizenship as a status entitling free movement has consolidated in the public awareness.

As the examples demonstrate, Europe was primarily understood as the EU in the discussions related to citizenship. Some participants built an active relationship to this EUrope and saw themselves as agents in 'constructing Europe' (e.g. ML1). One of them explicitly framed European identity with the EU. She sought to develop and disseminate this identity and raise awareness of the EU as not dry, but thrilling. She was eager to be involved in enhancing the benefits provided by the EU in everyday life. She welcomed the "opinion differences of EU citizens" and saw Europe as a construction process involving joint problemsolving and increasing understanding and tolerance (ML9).

Conclusions: EU Projects as Politics of Belonging

Ethnographic research on implementing the EU's Culture programme, explored through an individual project, revealed various conceptions of Europe. Most importantly, it helped us to understand how the project participants themselves conceptualized Europe and their own relations to it. The role of Europe was central to their experiences, which reflects the importance of the notion of Europe in discursive identity building on the other levels. In the meso-level ECC discourses, Europe is a key concept through the project's core component, European citizenship, and the related aim of creating European identity. In the macro-level EU documents related to the Culture programme, the focus is naturally on Europe, and the most diverse issues are framed as European.

The participants depicted Europe as simultaneously united and diverse. There was thus a clear continuity from the discourse of the Culture programme, as well as other EU discourses, in which conceptualizations of Europe balance between unity and diversity, in the spirit of the official EU slogan "United in diversity". The participants drew on their own experiences to construct their understandings of and sense of belonging to Europe. Their constructions demonstrate that they saw the unity and diversity of Europe on a practical everyday level rather than as distant high-level EU institutions and abstract principles, or formal national and regional diversity (see also Chapter 6).

Several participants saw Europe as under construction, referring to the present and the future in this context, but also to the historical background of the construction process. In the participants' accounts, Europe often meant the $\mathrm{EU}$, as is the case in the documents related to the Culture programme and in 
other macro-level EU discourses. Similarly, in the meso-level texts on coordinating the ECC, the Europe usually meant the EU, because the terms Europe and the EU were used interchangeably. Moreover, the core concept of the project, European citizenship, referred to Union citizenship, which is an EU institution.

Despite the frequent overlapping of Europe and the EU in the participants' discussions, their notion of Europe is broader and goes beyond the EU. They framed their conceptions of Europe with the changing geographical perceptions of the continent and shifting borders within and around it. Mobility was central to participants' conceptions of Europe and their own feeling of Europeanness. They supported the idea of a 'borderless Europe' and mobility across the state borders without formalities. Using the Euro currency and foreign languages were also highlighted as building blocks of their feeling of Europeanness. Nevertheless, some participants regarded the right to free movement as a means of establishing a boundary to keep out non-EU citizens and viewed Europe as a privileged place as concerns freedom of mobility and some other rights. Above all, participants expressed that European belonging develops through personal relations and connections across state borders, enabled by mobility. These views are connected to the discourses of the EU's Culture programme, in which mobility of cultural actors, products, and services is a key objective. The goal of the Culture programme is to develop a European identity "from the grass roots" precisely by fostering cross-state mobility and interaction (EC 2004, 4; see also EP\&C 2006, 2, 4). In the meso-level discourses of the ECC project, mobility was not explicitly discussed but obviously the project itself enabled mobility and created cross-border interaction.

With few exceptions, the participants felt that the ECC project contributed to the development of their European belonging. They conceptualized the ECC as a space of mobility, making art, intercultural learning, networking, and speaking various languages. They considered participating in the ECC project as something 'European', and felt that doing so made Europe present to them. The project as such can thus be viewed as creating a European "lived space" (Lefebvre 1991, 362) that was enlivened through personal experiences. Hence, EU projects have the potential to create European belonging as defined in the objectives of the EU programmes through enabling interaction and connections between citizens across state borders - even if they do not include any discussions or practices directly focusing on Europe. As such, the EU projects engage citizens in the EU, and are thus inherent in the EU's politics of belonging. They are examples of "specific political projects" (Yuval-Davis 2006, 197) seeking to construct EUrope and belonging to it simultaneously from above and from below.

The ethnographic research revealed both continuities and disruptions between the macro, meso, and micro levels in the ways in which citizenship 
was understood in the European context. The documents regarding the Culture programme explain the role of cultural and linguistic cooperation in making "European citizenship a tangible reality by encouraging direct participation by European citizens in the integration" (EP\&C 2006, 1). In the mesolevel ECC discourses, this was explicit since European citizenship was taken as the project's core content. On this level, the ECC was envisioned as a platform to encourage public debate on citizenship and students' participation in it through art. The ECC project sought to contribute to the development of a European-level public sphere, trying to build Europe as a political community, as a community of citizens acting in a public sphere. The difference to the macro level is that even though the programme documents highlight the idea of citizenship of the Union, they do not pay attention to public debate and citizens' participation as political agency.

The aspiration to promote debate on the notion of citizenship was not present in the project practices observed in our ethnographic fieldwork in the Roots lab (but may have been present in other art laboratories). Concomitantly, citizenship was difficult for the participants to discuss, even though they were participating in a project with citizenship as its main topic. Only few of them saw themselves as political agents on the European scale, even though most if not all identified themselves as European citizens in some way. The majority did not refer to political action or public debate, which means that there is a considerable break between the meso- and the micro-level discourses within the project. The participants may have seen Europe as too broad a context for citizenship understood as civic action in the public sphere. The fact that participants discussed citizenship relatively little if at all underlines this break.

Common to the macro-, meso-, and micro-level discourses is the close link between citizenship and European identity. The decision of the Culture programme highlights European citizens' identity - consisting of common cultural values and roots as well as cultural and linguistic cooperation - and connects the key objective, creating a European cultural area, to "encouraging the emergence of European citizenship" (EP\&C 2006, 1, 4). The meso-level texts follow and use this official programme rhetoric. Thus, the ECC can be interpreted as implementing the programme's key aims concerning identity and citizenship. In the micro-level discourses, identity and citizenship were also closely connected. For example, in response to the question about citizenship, interviewees often discussed their national and European identifications.

The notion of banal Europeanism, developed by Laura Cram (2009, 2012) can help us to interpret these findings. This notion is based on the well-known concept of banal nationalism by Billig (1995) that claims that nations are invisibly produced and reproduced in everyday lives through routine symbols and 
habits of language. Similarly, according to banal Europeanism, everyday routine practices and daily encounters with EU symbols may reinforce (unconscious) identification with Europe. Facing EU frequently and repeatedly through symbols, media discourses and other everyday situations may lead to the 'normalization' of the EU as a legitimate political authority. In the ECC interview data, the EU was primarily seen in terms of a functional actor often taken for granted. The project participants indeed closely linked the EU to their perceptions of Europe and their micro-level experiences related to Europe, such as the Euro currency and border-free mobility. When discussing Europe and their own relations to it, the participants combined their everyday experiences with the 'banal', well-known and frequently repeated representations and narratives, including values and 'universal' ideas such as peace and democracy, that are often related to Europe. In this respect, they echo the EU's grand narrative about the EU integration. The characteristics that the participants attached to Europe are also part of the official EU narratives, even though the participants discussed them through their own personal experiences.

It can be concluded that the EU's politics of belonging through identity building was present in the ECC at the macro, meso, and micro levels. Discourses at all levels, despite their differences, sought to create identity for both EUrope and its inhabitants primarily through cross-border interaction and interpersonal relations, enabled by the ECC project and other similar opportunities for mobility across state borders. These elements were seen more important than civic participation in bridging the gap both between the EU and citizens and between citizens themselves. The ethnographic research on this one project funded through Culture programme made visible the differences and similarities in the notions of Europe constructed at different levels of the project. As such, the analysis produced a more nuanced understanding of EU cultural policy and perceptions of Europe in the context of multilevel and participatory governance of the EU.

\section{References}

Antwerp Declaration. 2015. Antwerp Declaration for a Stronger Promotion of Student Culture. Received at the dissemination conference of the ECC project in Antwerp, 26 June 2015 .

Arendt, H. 1998 [1958]. The Human Condition. Chicago: The University of Chicago Press. Art Catalogue. 2015. Received at the dissemination conference of the ECC project in Antwerp, 25 June 2015.

Billig, M. 1995. Banal Nationalism. London, Thousand Oaks, New Delhi: Sage. 
Čeginskas, V. L. A. 2016. “I am Europe’. Experiences of Multiple Belonging.” Ethnologia Fennica, 43: 72-88. Accessed 23 April 2020. https://journal.fi/ethnolfenn/article/ view/65636/26505

Cram, L. 2009. "Identity and European Integration: Diversity as a Source of Integration." Nations and Nationalism 15 (1): 109-128.

Cram, L. 2012. "Does the EU Need a Navel? Implicit and Explicit Identification with the European Union." Journal of Common Markets Studies 5o (1): 71-86.

Detailed Description of the project European Citizen Campus (ECC). n.d. Received from the project coordinator by e-mail 15 May 2014.

EC (European Commission). 2004. Proposal for a Decision of the European Parliament and of the Council Establishing the Culture 2007 Programme (2007-2013). $\operatorname{COM}(2004) 469$ final. Brussels: European Commission. Accessed 10 January 2020. http://www.europarl.europa.eu/registre/docs_autres_institutions/commission _europeenne/com/2004/o469/COM_COM(2004)0469_EN.pdf

EP\&C (European Parliament and the Council). 2006. "Decision No 1855/2006/EC of the European Parliament and of the Council of 12 December 2006 Establishing the Culture Programme (2007 to 2013)." Official Journal of the European Union L 372: $1-11$.

Fleck, J. 2015. "European Citizen Campus: Negotiating European Identity during an Intercultural Art Workshop." Master thesis in Learning and Communication in Multilingual and Multicultural Contexts, University of Luxembourg.

Lefebvre, H. 1991. The Production of Space. Oxford: Blackwell.

Mäkinen, K. 2019. "Interconceptualising Europe and Peace: Identity Building under the European Heritage Label." In Dissonant Heritages and Memories in Contemporary Europe, edited by T. Lähdesmäki, L. Passerini, S. Kaasik-Krogerus, and I. van Huis, 51-78. New York: Palgrave Macmillan.

Treaty of Rome. 1957. Traité instituant la Communauté Économique Européenne et documents annexes. 11957E/TXT. Accessed 20 April 2020. https://eur-lex.europa.eu/ legal-content/FR/TXT/PDF/?uri=CELEX:11957E/TXT\&from=EN

Walters, W., and J. H. Haahr. 2005. Governing Europe. Discourse, Governmentality and European Integration. London: Routledge.

Wiesner, C., A. Björk, H.-M. Kivistö, and K. Mäkinen. 2018. "Introduction: Shaping Citizenship as a Political Concept." In Shaping Citizenship: A Political Concept in Theory, Debate and Practice, edited by C. Wiesner, A. Björk, H.-M. Kivistö, and K. Mäkinen, 1-16. New York and Abingdon: Routledge.

Yuval-Davis, N. 2006. "Belonging and the Politics of Belonging." Patterns of Prejudice 40 (3): 197-214. 